\section{Mapping agricultural performance and environmental parameters aimed at generic regional studies}

Bakos Károly Livius - Dobos Attila - Nagy János Debreceni Egyetem Agrár- és Gazdálkodástudományok Centruma, Mezőgazdaság-, Élelmiszertudományi és Környezetgazdálkodási Kar, Földhasznosítási, Műszaki és Területfejlesztési Intézet, Debrecen karoly.bakos@agr.unideb.hu

\section{SUMMARY}

In this paper we present the interim results and the methodology applied to create web GIS ready cartographic representations of agricultural performance related information and environmental parameters. The main aim of the research is to eventually create a web GIS based decision support system that can enable decsision makers and general users to create useful and representative map layouts of certain environment and agriculture related phenomena that can be easily analyzed and interpreted to make strategic decisions on environmental issues. In this aim the initial steps are to evaluate the available data for cartographic representation, analyze the possibilities of visualization, create a GIS ready data structure and implement the database and revise additional possibilities to incorporate further environment related datasets of auxiliary sources. The main results of the study are a comprehensive set of visual layouts that could serve as guideline for mapping statistical information of agriculture and some steps towards the incorporation of environmental parameters to the system.

Keywords: agricultural performance, decision support system, mapping, GIS

\section{INDRODUCTION AND BACKGROUND}

Decision support systems are widely used in analysis and interpretation of environment and agriculture related processes and phenomena (Papamichail and French, 2005). There are many kind of such system available in the technical literature that can serve certain well defined purpose and targeting to address certain issues arising. In environmental and earth sciences with the penetration of Geographic Information Systems (Herrero-Jiméne, 2012) it became possible to analyze certain phenomena in the spatial domain. This can lead more accurate decisions over environmental issues and allows the incorporation of spatially distributed information to be treated in its domain. This exceptional feature of GIS systems enable to build very specific GIS systems that serve as decision support system tool by combining the descriptive multivariate attribute variables with exact location in the spatial domain as in (Wanmei Ou et al., 2010). In this study we introduce the initialization of such spatially enabled decision support system (Seffino et al., 1999) to address issues arising in agricultural production and environmental treatments in the same time. For the purpose of agricultural analysis we use standard agricultural performance related datasets (Briassoulis, 2007) combined with traditional statistical information that is collected and stored in a non optimized manner for spatial representation and modeling. During this initial phase of the research elementary steps were defined to build the geospatial database, establish a way to convert the non-spatial datasets to geodata by geocoding them, and a number of visual representations were created to assess the best way of presenting users with the data. For this purpose numerous indices were also used to exploit second and further order information of the datasets. Such indices are the D'Hort index (Cox, 1991) or index of large heads per capital.

\section{AIMS AND OBJECTIVES}

The main aim of the research is to establish a systematic and well designed cartographic representation scheme for mapping agricultural performance and environmental parameters in spatially enabled decision support systems. To initialize the research the following key objectives were identified:

- Analysis of available datasets for cartographic products.

- Evaluate the possibilities and generate meaningful agricultural performance related indices that can be visualized in a decision support system.

- Evaluate the requirements of environmental parameters to incorporate into the DSS.

- Create test visualizations and composite cartographic representations of the.

\section{MATERIALS AND METHODOLOGIES}

As basic input source of information the datasets available from the Hungarian Central Statistical Office (KSH) (KSH website, 2012) were obtained and parsed. Also the Agricultural Yearbook of the Hungarian Central Statistical Office was used and information was extracted. As a third input source the Agricultural Census data of Hungary was also incorporated to the research. Agriculture in Hungary plays a major role in the economy of the country. The $85 \%$ of the country is suitable for agricultural production. The main factors that are driving agriculture in Hungary are the generally good quality and fertile land, the favorable climate, the appropriate biotic and abiotic factors and the availability of water. The agricultural production however is below $10 \%$ of the GDP and nearly $8 \%$ of the total population is employed in agriculture. During the years the share of agriculture in the economy has shrieked but until now agriculture contributes to the foreign exchange of the country significantly. Hungarian agricultural fields occupy nearly 2 thirds of the total land area of the country. Agricultural crops cover approximately the $80 \%$ of agricultural areas while permanent grasslands have 1.5 million Hectares share from the lands. The main agricultural crops are cereals that account for the $80 \%$ of total arable land. Maize and wheat are providing nearly $85 \%$ of the 
arables and and $90 \%$ of the arable export of the country. Sunflower, sugar beet, vegetables and barley are the other common products of Hungarian agriculture. The share of agriculture in the GDP is constantly decreasing starting from the 90s and from approximate 8\% in 2011 it provided only the $3 \%$ of the GDP. While Hungarian agriculture is traditionally responsible for providing around $3 \%$ of the national economy's GDP - that is double the average within the Union - and the agricultural business as a whole makes up 10-12\% of the Hungarian economy (Szakáll et al., 1993). In the Table 1. below the most important land use data is provided from the year 2007.

Basic descriptive data of Hungarian agricultural performance in 2007

Table 1.

\begin{tabular}{lcl}
\hline \multicolumn{1}{c}{ Description } & Value & \multicolumn{1}{c}{ Unit } \\
\hline Total Area of the country & 93030 & $\mathrm{~km}^{2}$ \\
Agricultural land & 58070 & $\mathrm{~km}^{2}$ \\
Agricultural land per 1000 population & 5.8 & $\mathrm{~km}^{2}$ per 1000 population \\
Agricultural land (percentage of total area) & 62.4 & $\%$ of total area \\
Agricultural land (percentage of land area) & 64.8 & $\%$ of land area \\
Arable land & 45920 & $\mathrm{~km}^{2}$ \\
Arable land per 1000 population & 4.6 & $\mathrm{~km}^{2}$ per 1000 population \\
Arable land (percentage of total area) & 49.4 & $\%$ of total area \\
Arable land (percentage of land area) & 51.2 & $\%$ of land area \\
Arable land (percentage of agricultural land) & 79.1 & $\%$ of agricultural area \\
Permanent crops & 1980 & $\mathrm{~km}$ \\
Permanent crops per 1000 population & 0.2 & $\mathrm{~km}^{2}$ per 1000 population \\
Permanent crops (percentage of total area) & 2.1 & $\%$ of total area \\
Permanent crops (percentage of land area) & 2.2 & $\%$ of land area \\
Permanent crops (percentage of agricultural land) & 3.4 & $\%$ of agricultural area \\
Permanent meadows and pastures & 10170 & $\mathrm{~km}^{2}$ \\
Permanent meadows and pastures per 1000 population & 1.0 & $\mathrm{~km}$ per 1000 population \\
Permanent meadows and pastures (percentage of total area) & 10.9 & $\%$ of total area \\
Permanent meadows and pastures (percentage of land area) & 11.3 & $\%$ of land area \\
Permanent meadows and pastures (percentage of agricultural land) & 17.5 & $\%$ of agricultural area \\
Forest area & 20036 & $\mathrm{~km}^{2}$ \\
Forest area per 1000 population & 2.0 & $\mathrm{~km}$ per 1000 population \\
Forest area (percentage of total area) & 21.5 & $\%$ of total area \\
Forest area (percentage of land area) & 22.4 & $\%$ of land area \\
Other land & 11504 & $\mathrm{~km}^{2}$ \\
Other land per 1000 population & 1.2 & $\mathrm{~km}$ per 1000 population \\
Other land (percentage of total area) & 12.4 & $\%$ of total area \\
Other land (percentage of land area) & 12.8 & $\%$ of land area \\
\hline
\end{tabular}

The basic environmental properties of Hungary are shown in the maps in Figure 1. with the Corine land cover map, the generic soil map and climate related information.

The maps and geographic data available for Hungary is having the EOV (Unified National Projection System) projection system and HD 1972 datum as base surface (Zaletnzik, 2004) for projection. This projection system is very interesting projection system and raise some challenges in GIS and cartographic works.

Given the research goals of this study multiple areas of cartography and GIS is being involved. There were tasks related to preparation and cleaning-up the data, store and processing in Geographic Information System and also challenges in designing and creating the best cartographic representations of the datasets stored in the database. Given the diverse variety of tasks a complete framework of information processing was designed and individual steps and methods are listed below.
In order to obtain the maps and the cartographic representations of the country the statistical data had to be rearranged and processed to meet the requirements of a GIS based analysis database back-end. Each statistical table was parsed and information related to NUTS 3 regions were extracted and remapped into the database. In many cases very limiting factor was the muftidimensionality of the datasets having different type of data in each line hence careful attention was paid on gathering all useful information from the data and remap the matching lines into new records of the database instead of discarding them. After collecting all useful information the gathered table was revised and cleaned up and exported to database. After the database was ready we applied a spatial join of the tabular information to the spatial data available for Hungary. An overview of the generic work flow of preprocessing of the datasets is shown in Figure 2. below. 
Figure 1: Environmental conditions of Hungary shown by the (a) CLC2000 land cover map, (b) the generic soil map of Hungary, (c) average precipitation and (d) average temperature of 5 years of measurement

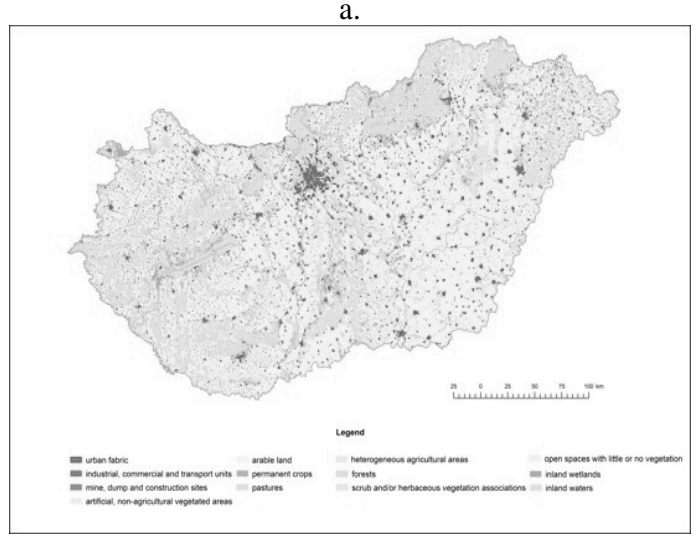

b.

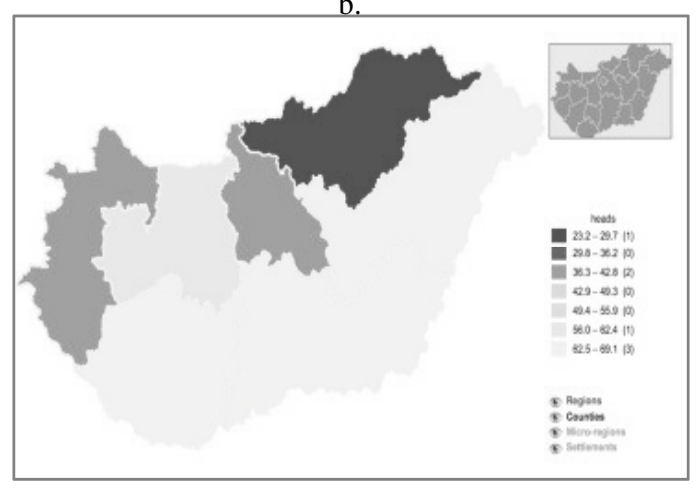

c.

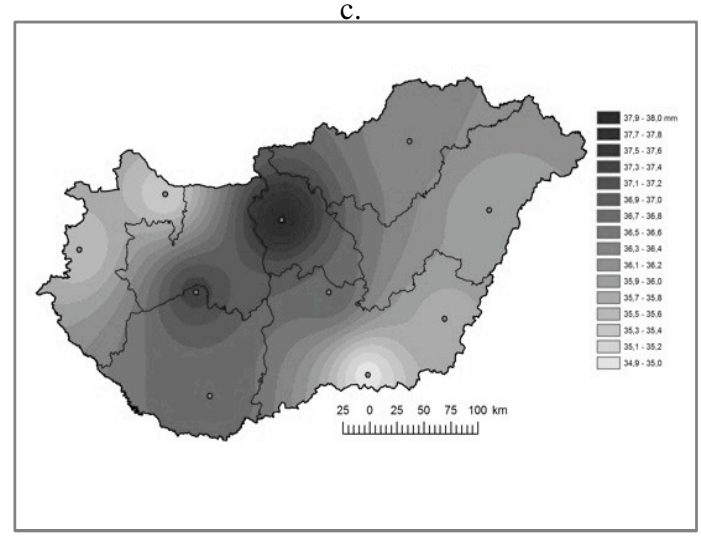

d.

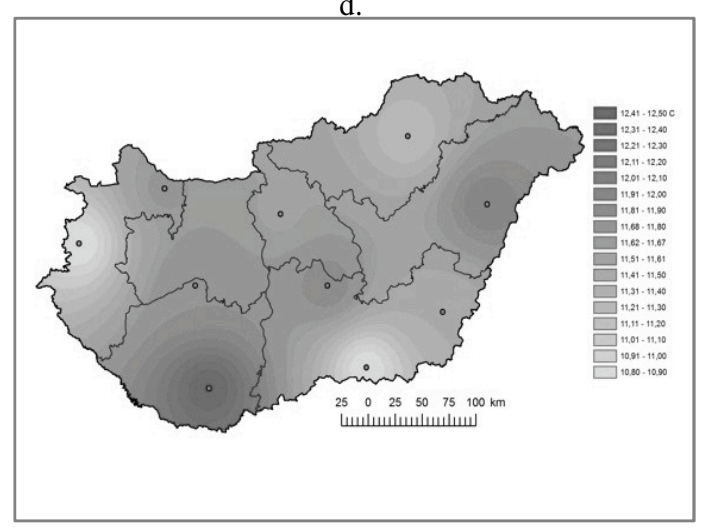

Figure 2: Generic work flow used in the study to preprocess statistical datasets and create GIS database for data visualization and analysis

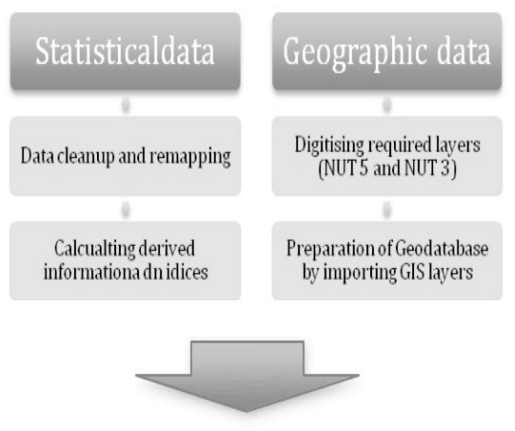

Joining spatial and tabular data and finalise GIS database

Spatial analysis of the data and gnerating map layouts

Generation of cartographic products and representations

In order to explore the meaning of the measured statistical data some indices were derived that are more meaningful than the individual statistical records for the counties. These indices include the:

- index of D'Hondt (of successive quotients) as a method of cropland structure or animal breeding structure typology;

- Large Heads per ha of agricultural land as an index of animal breeding importance in agriculture;

- new dwellings number per thous. of inhabitants in rural areas (index of economic circumstances in rural areas);

- length of public sewerage network per one kilometer of water pipe network (index of infrastructural circumstances in rural areas);

- population under 19 and over 60 per 100 of population 20-59 and feminization index in age 20-29 (indexes of demographic circumstances in rural areas).

Such indices were generated by extracting the information from the statistical data and processing them according the index value in concern.

In terms of environmental parameters an attempt was made to delineate areas where water stress can occur and combine the information into the geodatabase. A particular challenge was to delineate the areas firs and secondly to find a useful representation of the multitemporal data. The exact methodology is not part of this article in concern and is being published elsewhere therefore in this paper we only focus on the representation challenge of multitemporal data. The delineation procedure however was carried out using a recursive optimization algorithm, combined with the Class Probability Membership Value based ensemble misappropriation (PMVE) algorithm (Bakos and Gamba, 2010, 2011) with the criterion of using only Spectral Angle Mapper (SAM) [Ref] in a supervised manner. For the delineation multitemporal series of Landsat TM remote sensing imagery was used. The map of study area with the available ground truth is shown in Figure 3. below and the series of satellite images are depicted in Figure 4. 
Figure 3: The study are of mapping environmental parameters near to Hajduszoboszlo, Hungary with the ground truth data available

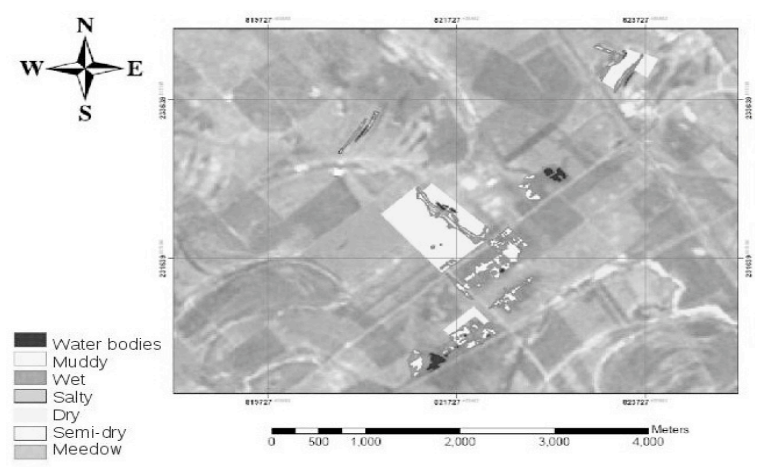

Figure 4: The satellite images available for the study from (a) April, (b) May, (c) June, (d) July, (e) August and (f) October

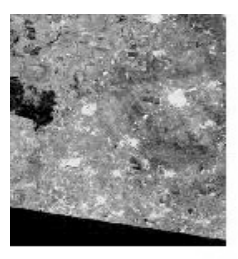

a

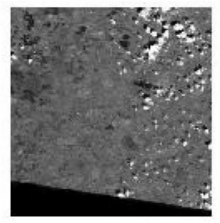

d

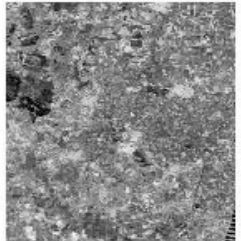

b

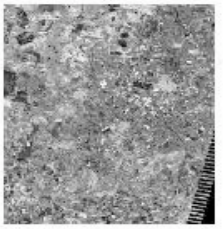

e

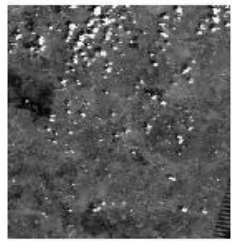

C

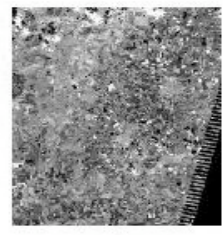

\section{RESULTS}

The main results of this paper is a series of map layouts generated to represent statistical performance related information of Hungarian agriculture and the visualization of the developed indexes for the country. These initial steps were carried out on two distinct administrative levels of Hungary. In one hand the visualizations were tested on NUTS 3 and NUTS 5 level and special attention was paid on enabling some scale dependent visualizations therefore the two separate databases were consolidated.

Some examples of the derived indices and performance related information visualized in map layouts are shown in figures below (Figure 5. and 6.).

Hes visualizations are examples of the products of mapping agricultural performance and statistical data. Further maps will be available on-line as the tool will be fully functional (Figure 7.).

Example of mapping environmental parameters is showcased here in a form of mapping inland water bodies. The main challenge here is to accurately visualize multitemporal information and enable the viewer to make accurate decisions afterward. The map layouts generated by the study are compatible with the performance related data therefore with the careful selection of visualization extent can be viewed parallel in the desired decision support tool.

Figure 5: Vegetation distribution - main crops composite map

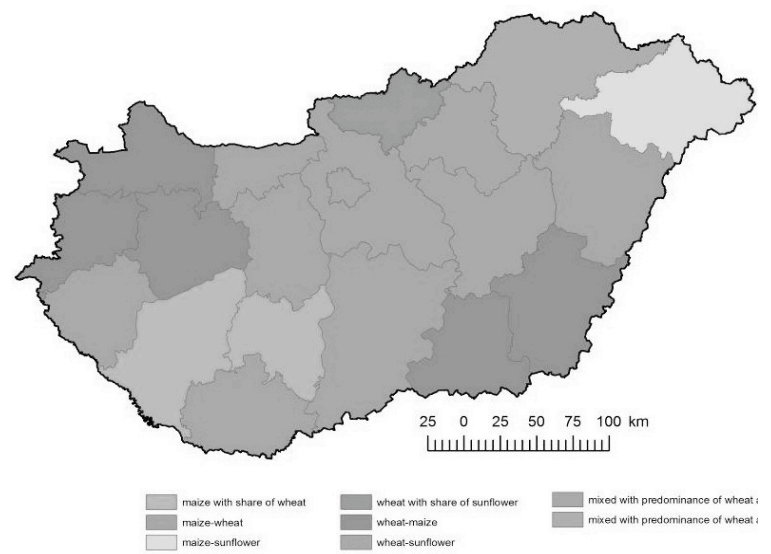

showing the shift towards certain main crops in each NUTS 3 units

By combining together the derived information the inland water extent can be defined as a composite of aggregated summary of the individual delineations. Such example is shown below in Figure 8.

\section{DISCUSSION AND CONCLUSIONS}

In this paper it is demonstrated that mapping and visualizing of agricultural performance related data is possible in a fashion to be suitable for storage and analysis in Geographic Information Systems. Furthermore it is also possible to derive additional datasets from the pure statistical information that is not geocoded. These led towards to a GIS based decision support tool that can answer relevant questions in regional development and regional studies. The developed indices show high potential in representing some of the aspects of the agriculture that are otherwise hidden in the dataset deeply thus not enabling decision makers to consider a full spectrum of available data. The spatially enabled database structure is a proper choice for agriculture related information management and analysis by enabling a broad view and holistic approach to certain problems incorporating the spatial domain into the decision feature space. Apart from visualizing basic statistical data and derived indices in the system it was also demonstrated that environmental information derived from ancillary sources such as remote sensing imagery can be incorporated to the same system therefore enabling the simultaneous view of performance and actual conditions in the same area.

Further steps along the same direction are already planned. Many open issues are still to be addressed and it can be concluded that importing further datasets to the same geodatabase will led to a highly demanded tool in environment and agricultural performance related decision making procedure. 
Figure 6: The distribution and yield of $\mathbf{4}$ main crop types in Hungary a composite map series of area used by production and yield obtained by production of (a) winter wheat, (b) winter barley, (c) sugar beet and (d) corn
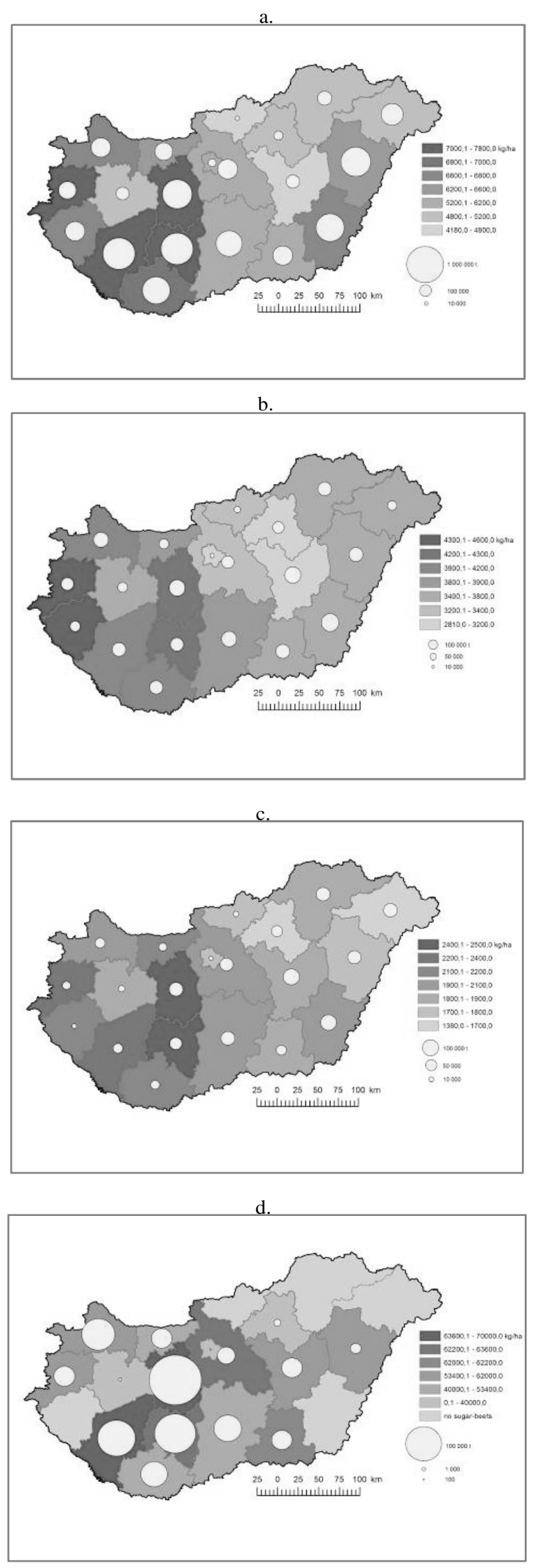

Figure 7: Water pressure detected by remote sensing data interpretation in (a) April, (b) May and (c) October on the study are in terms of inland water
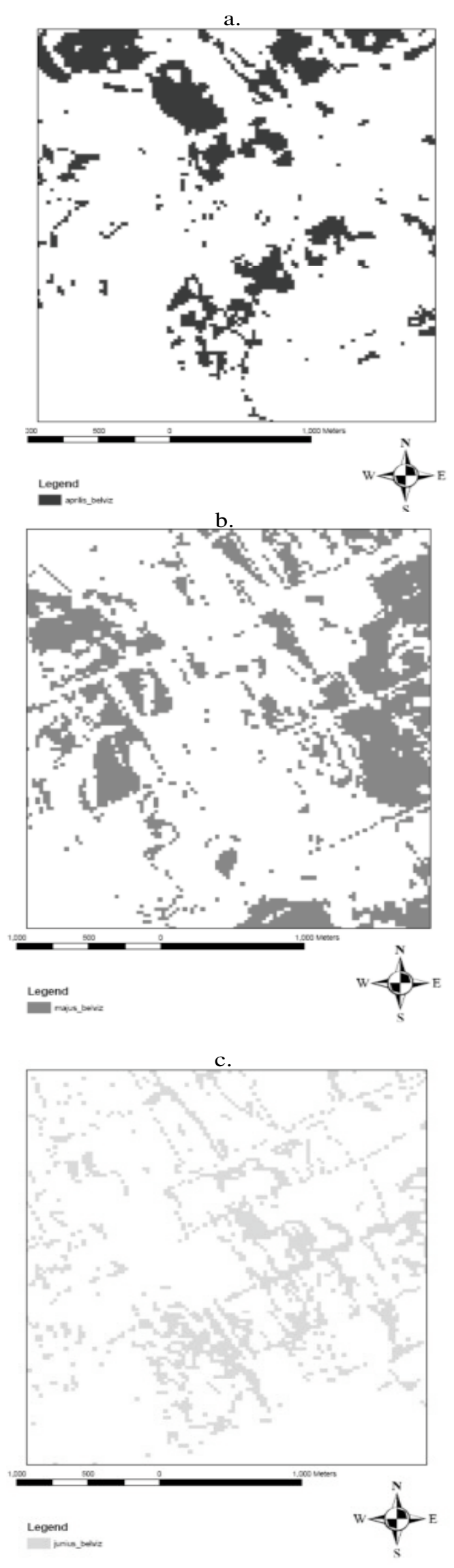
Figure 8: Composite map of vegetation and inland water bodies estimated using multitemporal satellite image data acquired in April, May and October to detect vegetation and inland water patches

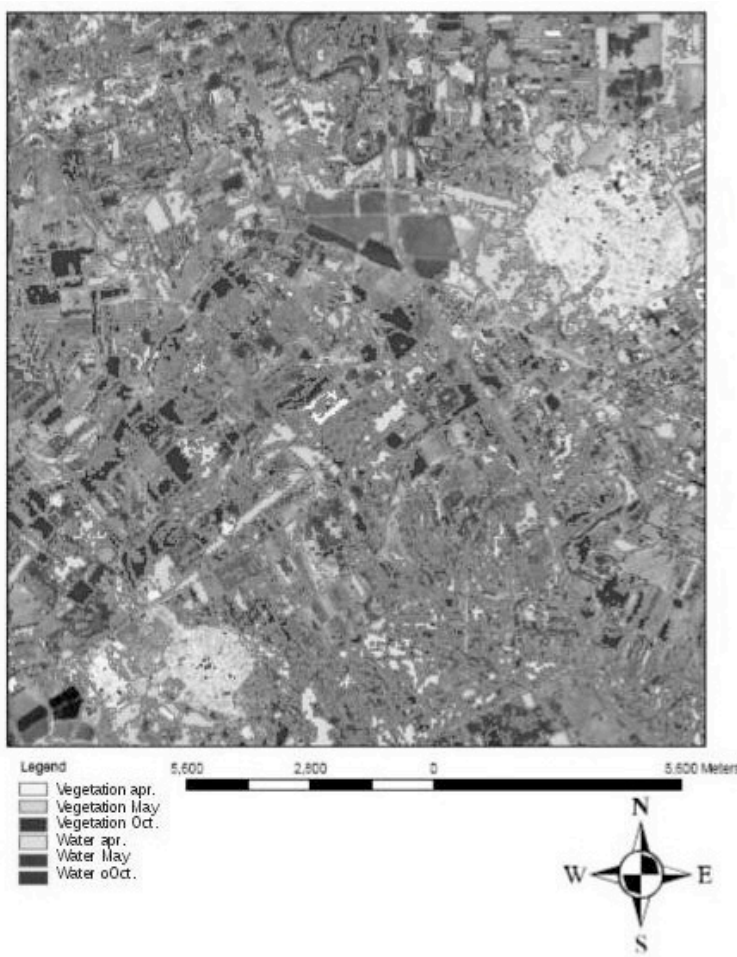

In the near future the implementation of a publicly accessible on-line GIS based decision support tool is expected therefore models will be developed and new indices and visual representations are needed. Novel methodologies are also required to further increase the potential of the tool by developing further compatible datasets regarding environmental conditions of the area in concern. An especially desired approach would be to retrieve accurate information on detailed land cover and soil structure of the areas that are analyzed using the tool and these basic information would help to fine tune each analysis. Hyperspectral field based and airborne techniques show great potential in these fields.

\section{ACKNOWLEDGMENT}

This project work was partially founded by the FP7-REGPOT-2010-1 UD_AGR_REPO Capacities programme run by the University of Debrecen, Institute for Land Utilisation, Technology and Regional Development. The Institute of Geography and Spatial Organisation of the Polish Academy of Sciences provided significant amount of work and knowledge for the work.

\section{REFERENCES}

Papamichail, K. N.-French, S. (2005): Design and evaluation of an intelligent decision support system for nuclear emergencies. Decision Support Systems. 41. 1: 84-111.

Herrero-Jiménez, C. M. (2012): An expert system for the identification of environmental impact based on a geographic information system. Expert Systems with Applications. 39. 8: 6672-6682.

Wanmei, Ou-Wells, III. W. M. -Golland, P. (2010): Combining spatial priors and anatomical information for fMRI detection. Medical Image Analysis. 14. 3: 318-331.

Seffino, L. A.-Bauzer Medeiros, C-Rocha, J. V.-Yi, B. (1999): Woodss - a spatial decision support system based on workflows. Decision Support Systems. 27. 1-2: 105-123.

Briassoulis, D. (2007): Analysis of the mechanical and degradation performances of optimised agricultural biodegradable films. Polymer Degradation and Stability. 92. 6: 115-132.

Cox, G. W. (1991): SNTV and d'hondt are 'equivalent'. Electoral Studies. 10. 2: 118-132.

KSH website (2012): www.ksh.hu
Szakál, F.-Illés, Cs. B. (1993): Problems and prospects of redirecting Hungarian agriculture towards sustainable development. Landscape and Urban Planning. 27. 2-4: 223-229.

Zaletnyik, P. (2004): Coordinate transformation with neural networks and with polynomials in Hungary. International Symposium on Modern technologies, education, and professional practice in geodesy and related fields. Sofia. Bulgaria. 471-479.

Bakos, K.-Gamba, P. (2010): Efficient combination of multiple hyperspectral data processing chains using binary decision trees. Hyperspectral Image and Signal Processing: Evolution in Remote Sensing (WHISPERS). $20102^{\text {nd }}$ Workshop. 1-4.

Bakos, K.-Gamba, P. (2011): Hierarchical Hybrid Decision Tree Fusion of Multiple Hyperspectral Data Processing Chains. Geoscience and Remote Sensing. IEEE Transactions. 49. 1-2: 388-394. 